and to emphasise the strengths and shortcomings of the professional care available for them.

In London, the running down of mental hospitals has superceded adequate community provision and homeless, mentally ill people often face extreme difficulty in finding any sort of medical care. In recent years there have been severe cutbacks in the building of new houses. Housing corporations have reduced their funding and this has exacerbated the situation. Furthermore, public acceptance of mentally ill people in the community is difficult to achieve.

The professional network for aftercare is sadly often deficient. The Department of Health has asked for new discharge policies, with particular emphasis for people with special needs, such as the homeless mentally ill, but at present only one London borough has a policy for the discharge of homeless patients. In Haringey, no Section 117 discharge arrangements are available and statutory aftercare obligations fail because there are no approved social workers.

Dr Weller spoke of the three main groups of homeless people: the young, often with problems of employment and finance, who are sometimes mentally ill; middle-aged people who are often chronically destitute, some $40 \%$ of these mentally ill, with $22 \%$ actively deluded or hallucinating, and a third group homeless as the result of drug or alcohol abuse, maybe a consequence of mental illness.

The number of prosecutions of homeless people has doubled over the last two years and the Metropolitan Police are very concerned about the extent of vagrancy. The rate of conviction is directly proportional to the amount of homelessness and inversely proportional to availability of psychiatric beds.

CONCERN calls for emergency accommodation throughout the country, specifically for homeless mentally ill people; central funding for carers, a National Health Bed Bureau and provision from health authorities of some facility which can serve as a haven for mentally ill people with no fixed abode. It wants to see the closure programme for large city asylums postponed so that hospital and community facilities can run in parallel until such time that the community can manage independently.

\title{
The Seventh Annual Conference of the National Association for the Dually Diagnosed (Mental IIIness/Mental Retardation)*
}

\author{
N. Bouras, Consultant Psychiatrist and Senior Lecturer, United Medical and Dental \\ Schools, Guy's Hospital, London SE1 9RT
}

The National Association for the Dually Diagnosed (NADD) was started in the early 1980 s by a small group of people who recognised the collective need for an awareness and understanding of the needs of people with a mental handicap who also had a mental illness. The intention was to bridge the gap between the primary service providers and therapists by highlighting important skill deficits whether oriented to mental health or mental handicap.

The Boston conference was attended by over 300 participants of different disciplines, mainly from the USA and Canada, including psychiatrists, psychologists, other professional therapists, administrators, residential and day-care staff. The theme was 'Back to the Future, Lessons of the Past - Challenges of the Future'. The first keynote speaker, Professor Frank Menolascino of Nebraska University, referred to the fallacies of the past, such as the psychometric mental age as a measurement, untrainability and untreatability. He highlighted the need for future services to be small, integrated, using an array of options, * Conference held in Boston, Massachusetts in December 1990. focused on the development of long-term stable relationships, supported by regional tertiary care centres for short-term in-patient and long-term outpatient treatment. The other keynote speaker, Dr Ludwig Szymanski of Children's Hospital, Harvard Medical School, drew attention to the training needs of mental health professionals and the necessity for interdisciplinary training schemes.

The 60 presentations were divided into nine symposia covering areas such as assessment and diagnosis, treatment methods with emphasis on pharmacotherapy, behaviour therapy, psychotherapy, therapeutic interventions for aggression and challenging behaviour, as well as organisation and delivery of services and techniques to train staff appropriate skills.

Dr Steven Reiss described the increasing use of standardised instruments for assessment of psychiatric disorders and presented a wealth of recent data on children and adults. The importance of accurate psychiatric diagnosis and the use of psychotropic medication based on current advances was emphasised by the main speakers in these subjects: Dr 
Robert Sovner and Dr Henry Crabbe. Dr William Gardner reviewed the perspectives of behavioural methods used to treat people with mental handicap and aggressive behaviour by presenting a comprehensive, functional analysis of aggression with emphasis on environmental factors. The model of service provision which prevailed was community based with admission facilities whenever necessary. The complexities, various and sometimes conflicting principles and opinions of multidisciplinary team members were illustrated by $\mathrm{Dr}$ Mark Hauser.

It is encouraging and stimulating that an organisation such as NADD exists which focuses its activities on important issues and dilemmas, presented by the combined disability of mental handicap and mental illness. Although the challenge of correct diagnosis of psychiatric disorders in people with a mental handicap is not a new issue, it has received much more attention in recent years because the process of deinstitutionalisation and community care has increased the visibility of the problem. The coexistence of mental handicap and psychiatric disorder has serious effects on the person's daily functioning by interfering with educational and vocational progress by jeopardising residential placements, and by disrupting family and peer relationships. It can also greatly reduce the quality of life of people affected.

More collaborative work on an international level is required to disseminate knowledge and encourage the exchange of ideas in the field. My only suggestion is that perhaps it is time for NADD to reconsider its name, especially as there is an element of ambiguity, which might be applied to other conditions and hence lead to confusion.

\title{
The Mental Health Act and its agencies - are they working together?*
}

\author{
STEPHEN P. Tyrer, Consultant Psychiatrist, Royal Victoria Infirmary, Newcastle upon \\ Tyne NE1 4LP and Prudhoe Hospital, Prudhoe, Northumberland NE42 5NT; \\ and Timothy C. JeRram, Consultant Psychiatrist, High Royds Hospital, Menston, \\ Ilkley, West Yorkshire LS29 6AQ
}

The 1983 Mental Health Act gave increased responsibility to the Mental Health Act Commission and the Mental Health Review Tribunal to ensure safeguards in the treatment and detention of patients compulsorily admitted to hospital. Although most are agreed that the civil rights of patients admitted to hospital against their will are better protected under the new Act, some psychiatrists are irritated by the necessity to involve these bodies in what they regard as primarily clinical management. The North-East Division of the Royal College of Psychiatrists believed that debate on this issue might benefit both psychiatrists and others involved and this topic was chosen for the Annual Meeting of the Division in York on 28 September 1990. The meeting attracted other mental health care professionals and of the 144 participants almost one-third were not psychiatrists, but mainly social workers and psychologists. The sessions were chaired by the President of the College and Professor Donald Eccleston.

William Bingley, Chief Executive Officer of the Mental Health Act Commission and previously Legal Director of MIND, opened the meeting by asking whether the civil rights of the patient were *Annual Meeting of the North-East Division of the Royal College of Psychiatrists, 28 September 1990. adequately protected under the present legislation? He emphasised that civil rights were both positive, e.g. the right to care and to receive essential services as well as negative, such as the freedom to be protected from harm. How far patients were able to consent to treatment that impinged on their rights remained a matter of debate. Mr Bingley felt that there was a clear difference between those patients who were incapable of giving consent because of mental handicap or severe psychosis and those who were able to give consent but refused treatment. He believed that future revisions of the Mental Health Act should recognise the distinction between these two different sets of circumstances.

The work of the other main statutory agency, the Mental Health Review Tribunal, was discussed by Professor Sir John Wood, Chairman of this body. The most obvious injustices in the treatment of the mentally disordered patient arose because of detention in the wrong place because of lack of resources. The two basic rules that Sir John felt should always apply, that the patient should be kept in as free an environment as his illness permits and that once a move was indicated it should be offered with as little delay as possible, could often not be achieved because of the difficulty of arranging transfer to a less 